\title{
Large Renal Cyst Underestimates Split Function on Diuretic Radionuclide Renal Scan
}

\author{
Shrikant V. Solava ${ }^{a}$, Shailendra V. Savale ${ }^{a, b}$
}

\begin{abstract}
Radionuclide renal scan performed with (diethyle triamine penta acetic acid (DTPA), ethylene dicysteine (EC), mercaptoacetyltriglycine (MAG3), and dimercaptosuccinic acid (DMSA) provides split function between the two kidneys. Hence it is a valuable method to evaluate percentage function prior to nephrectomy. Nephrectomy may be done in a prospective renal donor or it may be done for a diseased kidney. In either case, the nephrologist/ urologist must ensure that the remaining kidney is able to sustain renal function post nephrectomy. We present a case where conventional renal scan had underestimated the split function due to a large posterior cortex cyst accounting for attenuation of radionuclide photons. Repeat scan in anterior view had eliminated this erroneous result. We could not find any such reported discrepancy despite extensive web-based search.
\end{abstract}

Keywords: Radionuclide renal scan; DTPA; Split renal function

\section{Introduction}

Radionuclide renal scan is a time-tested method to assess split renal function (SRF). It is deciding test prior to donor nephrectomy [1]. SRF is usually calculated by quantifying the radiotracer counts in the two kidneys between 2 and 3 min using computergenerated renogram. Several factors account for variation in split function such as body habitus, location of kidney (patient factor) and placement of region of interest, background subtraction (operator dependent factors), etc. A variation of $2-7 \%$ in the same patient on follow-up scan has been reported [2]. Various radionuclides have been used to estimate SRF. These are technetium (Tc)-99m-diethyle triamine penta acetic acid (DTPA), Tc-99mmercaptoacetyltriglycine (MAG3), Tc-99m-dimercaptosuccinic acid (DMSA). Computed tomography (CT) angiography and dynamic contrast-enhanced magnetic resonance (MR) angiography have also been used to calculate SRF [3, 4]. An 80-year-

Manuscript submitted December 23, 2020, accepted June 12, 2021

Published online September 28, 2021

aSPECT Lab, Nuclear Medicine Services, Pune, Maharashtra, India ${ }^{b}$ Corresponding Author: Shailendra V. Savale, Dr. Solav's SPECT Lab, Bavdhan, Pune, Maharashtra 411021, India. Email: drshailendrasavale@gmail.com

doi: https://doi.org/10.14740/wjnu422 old male was detected with renal mass on sonography. CT scan revealed an enhancing tumor in the interpolar region of left kidney. Tc-99m-DTPA renal scan showed compromised function of right kidney both qualitatively and quantitatively. The CT scan was reviewed and there was a large cyst in the posterior cortex of right kidney. Hence, the radionuclide scan was repeated in anterior view on another day (within 1 week). The repeat scan showed equal split function of the two kidneys. Thus, it is important to recognize that structural changes may result in misinterpretation of renal scan. Adequate precautions observed prior to imaging may prevent such errors.

\section{Case Report}

An 80-year-old male had vague pain in abdomen. He was hemodynamically stable. General examination was normal.

His sonography revealed a mass in lower pole of left kidney. CT showed a solid lobulated lesion at the lower and interpolar cortex of the left kidney with heterogeneous post contrast enhancement suggesting renal neoplasm. An exophytic cortical cyst at interpolar cortex of the right kidney was also noted. His biochemical profile was normal. Serum creatinine was $0.91 \mathrm{mg} / \mathrm{dL}$.

Radionuclide renal scan was performed in conventional posterior view using $4 \mathrm{mCi}$ of Tc-99m- DTPA administered intravenously with simultaneous acquisition of dynamic renal scan at the rate of $1 \mathrm{~min}$ per frame for $20 \mathrm{~min}$. Siemens single head E-cam gamma camera system was used with low energy high resolution collimator. Split function was assessed using computer-generated renogram. Region of interest was drawn by an experienced operator. The split function calculated was $82 \%$ from the left kidney and 18\% from the right kidney (Fig. 1a). As the structural appearance of the kidneys was quite normal on CT urography (Fig. 2a), and in view of a large cyst located on the posterior cortex of right kidney (Fig. 2b, c), the Tc-99mDTPA renal scan was repeated in anterior view on another day.

The repeat scan showed equal distribution of radiotracer qualitatively on sequential images (Fig. 1b). The glomerular filtration rate (GFR) calculated by Gates protocol showed satisfactorily functioning kidneys.

\section{Discussion}

The gold standard for assessment of renal function is GFR [5]. This must be done with inulin clearance, and is tedious and 

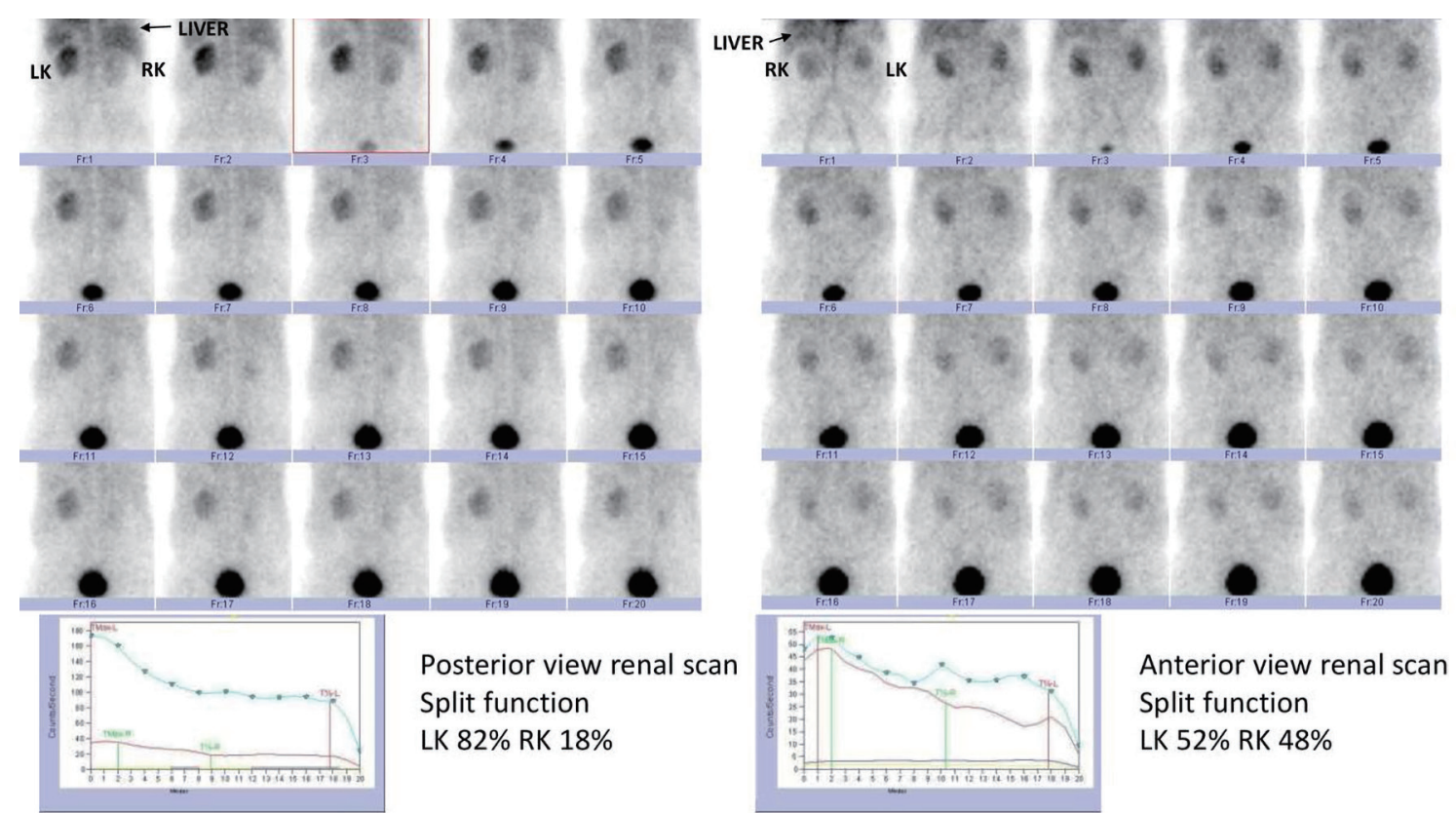

Figure 1. (a) The split function calculated by Tc-99m-DTPA renal scan in conventional posterior view. The split function calculated was $82 \%$ from the left kidney and $18 \%$ from the right kidney. (b) Tc-99m-DTPA renal scan was repeated in anterior view on another day. The repeat scan showed equal distribution of radiotracer qualitatively on sequential images. The split function calculated was $52 \%$ from the left kidney and $48 \%$ from the right kidney. Tc: technetium; DTPA: diethyle triamine penta acetic acid.

impractical for routine use on patients. Inulin is freely filtered by the kidneys. It is neither secreted nor reabsorbed by the tubules, and it is not metabolized [6]. A surrogate marker is creatinine clearance that measures the ability of the kidneys to clear creatinine from the circulation in $24 \mathrm{~h}$.

Serum creatinine is by far the easiest and first test to assess renal function. However, serum creatinine subject to physiologic variation depending on muscle mass (high muscle mass overestimates) and age (elderly may have false low estimates).
However, the GFR must fall below 50\% before there is rise in serum creatinine level. Thus, an elevated value clearly indicates compromised renal function, but a normal value does not eliminate need for further assessment of renal function [7]. Risk of chronic renal failure following radical nephrectomy is well known [8]. SRF using renal scintigraphy has been recommended when the creatinine is high, the GFR is low and where there are multiple renal tumors. Radionuclide renal scan is an important method to assess renal function when nephron sparing
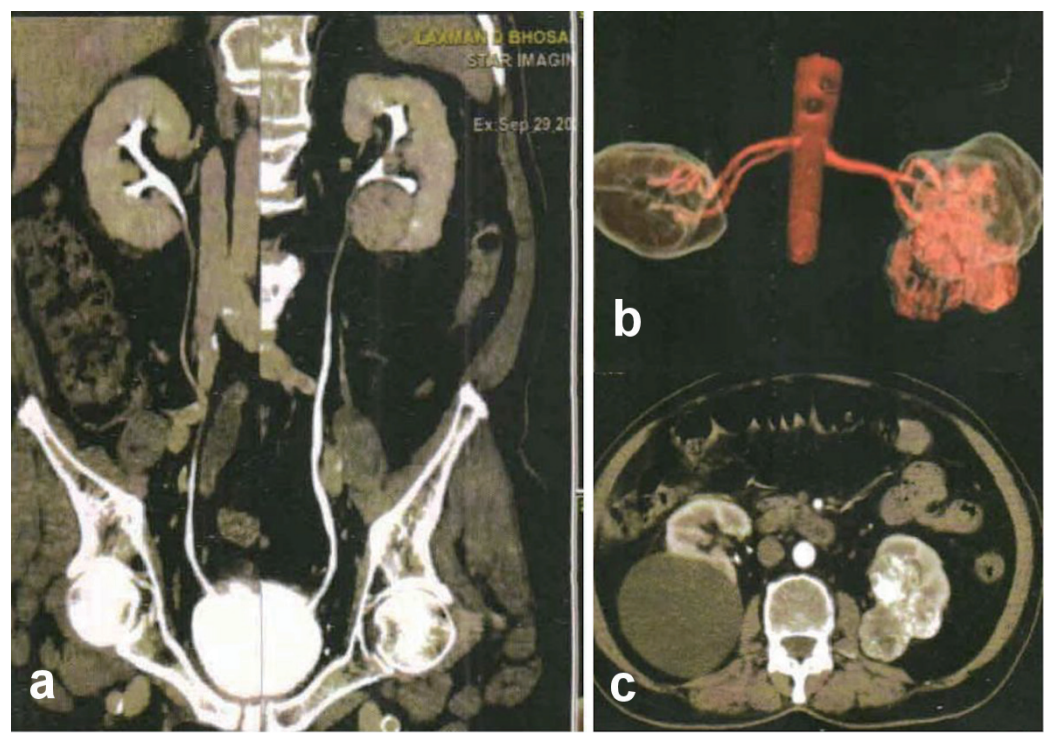

Figure 2. (a) Normal structural appearance of the kidneys on CT urography. (b, c) A large cyst located on the posterior cortex of right kidney. CT: computed tomography. 
surgery is performed [9]. Dynamic renal scintigraphy can be performed using Tc-99m-DTPA, Tc-99m-EC, Tc-99m-MAG3, and iodine-123 orthoiodohippurate. DTPA is the only agent that is purely filtered by the glomeruli. EC, MAG3 and hippuran are also secreted by the tubules, and hence are not suitable for assessment of GFR [10]. Errors in estimation of split function have been described due to high background activity in mild renal insufficiency [11]. Adequate precautions while processing the scan such as using correct frames for drawing the region of interest may overcome this issue. However, we did not come across any reference where a renal cyst underestimates the split function because of its position causing attenuation of photons. Our case highlights this particular aspect. A large posterior cortex renal cyst gives rise to blunted radionuclide counts (attenuation) in conventional posterior view of renal scan. Change of acquisition to anterior view eliminates with artifact.

Geist et al have reported estimation of split function using 18-F fluorodeoxyglucose (FDG) by positron emission tomography (PET) MR, and compared the results with Tc-99mMAG3 scan. Despite of difference in pharmacokinetics, their results showed good correlation between the two-radiotracer methods in estimation of split function, mean transit time and output efficiency [12]. Radionuclide renal scan is a useful method to assess renal function. It is required to assess split function prior to nephrectomy or nephron sparing surgery. However, it does not provide adequate structural information. Hence, it is important to know the structure of kidneys for accurate estimation of split function and obviate errors as demonstrated in this case report.

\section{Acknowledgments}

None to declare.

\section{Financial Disclosure}

None to declare.

\section{Conflict of Interest}

None to declare.

\section{Informed Consent}

Informed consent was obtained.

\section{Author Contributions}

Shrikant V. Solav as the guarantor contributed to the study design, literature search, clinical studies, experimental studies, data acquisition, data analysis, statistical analysis, and manuscript editing. Shailendra V. Savale contributed to the concepts, definition of intellectual content, literature search, data acquisition, statisti- cal analysis, manuscript preparation, and manuscript review.

\section{Data Availability}

The authors declare that data supporting the findings of the study are available within article.

\section{References}

1. Shokeir AA, Gad HM, el-Diasty T. Role of radioisotope renal scans in the choice of nephrectomy side in live kidney donors. J Urol. 2003;170(2 Pt 1):373-376.

2. Lin WY, Changlai SP, Kao CH. Normal ranges of renal physiological parameters for technetium-99m mercaptoacetyltriglycine and the influence of age and sex using a camera-based method. Urol Int. 1998;60(1):11-16.

3. Summerlin AL, Lockhart ME, Strang AM, Kolettis PN, Fineberg NS, Smith JK. Determination of split renal function by $3 \mathrm{D}$ reconstruction of $\mathrm{CT}$ angiograms: a comparison with gamma camera renography. AJR Am J Roentgenol. 2008;191(5):1552-1558.

4. Claudon M, Durand E, Grenier N, Prigent A, Balvay D, Chaumet-Riffaud P, Chaumoitre K, et al. Chronic urinary obstruction: evaluation of dynamic contrast-enhanced MR urography for measurement of split renal function. Radiology. 2014;273(3):801-812.

5. Davidson A, Cameron J, Grinfeld JP, et al. Renal function and testing of function. Oxford textbook of clinical nephrology. 1998.

6. Cole BR, Giangiacomo J, Ingelfinger JR, Robson AM. Measurement of renal function without urine collection. A critical evaluation of the constant-infusion technic for determination of inulin and para-aminohippurate. N Engl J Med. 1972;287(22):1109-1114.

7. Levey AS, Becker C, Inker LA. Glomerular filtration rate and albuminuria for detection and staging of acute and chronic kidney disease in adults: a systematic review. JAMA. 2015;313(8):837-846.

8. Huang WC, Levey AS, Serio AM, Snyder M, Vickers AJ, Raj GV, Scardino PT, et al. Chronic kidney disease after nephrectomy in patients with renal cortical tumours: a retrospective cohort study. Lancet Oncol. 2006;7(9):735-740.

9. Uzzo RG, Novick AC. Nephron sparing surgery for renal tumors: indications, techniques and outcomes. J Urol. 2001;166(1):6-18.

10. Blaufox MD, Aurell M, Bubeck B, Fommei E, Piepsz A, Russell C, Taylor A, et al. Report of the Radionuclides in Nephrourology Committee on renal clearance. J Nucl Med. 1996;37(11):1883-1890.

11. Sennewald K, Taylor A, Jr. A pitfall in calculating differential renal function in patients with renal failure. Clin Nucl Med. 1993;18(5):377-381.

12. Geist BK, Baltzer P, Fueger B, Hamboeck M, Nakuz T, Papp L, Rasul S, et al. Assessment of the kidney function parameters split function, mean transit time, and outflow efficiency using dynamic FDG-PET/MRI in healthy subjects. Eur J Hybrid Imaging. 2019;3(1):3. 